\title{
The term structure of interest rates as predictor of stock returns: Evidence for the IBEX 35 during a bear market
}

\author{
Adrian Fernandez-Perez \\ Departamento de Métodos Cuantitativos, Facultad de Ciencias Económicas y \\ Empresariales, Universidad de Las Palmas de Gran Canaria, Campus de Tafira, 35017 \\ Las Palmas de Gran Canaria Spain, adrian.fernandez102@alu.ulpgc.es
}

\begin{abstract}
Corresponding author: Fernando Fernández-Rodríguez
Departamento de Métodos Cuantitativos, Facultad de Ciencias Económicas y Empresariales, Universidad de Las Palmas de Gran Canaria, Campus de Tafira, 35017 Las Palmas de Gran Canaria Spain, ffernandez@dmc.ulpgc.es

Simón Sosvilla-Rivero

Departamento de Economía Cuantitativa, Facultad de Ciencias Económicas y Empresariales, Universidad Complutense de Madrid, Campus de Somosaguas, 28223

Madrid, Spain, sosvilla@ccee.ucm.es
\end{abstract}

\begin{abstract}
We present a model to forecast the probability of bear markets in the Spanish IBEX 35 with a congruent and concise parameterization which selects the explanatory factors from a wide set of variables like the yield curve of Spain, US and Europe, as well as several macro variables, and numerous leading indicators.

To this end, we first use a data-guided algorithm to select an in-sample optimal Probit model that is employed as a benchmark. We then form alternative Probit models obtained from combinations of levels, slopes and/or curvatures in the yield curve of Spain, US and Europe, as well as several macro variables and compare their estimated probability of bear markets in the out-of-sample period with that from the benchmark model. Our results suggest that the slopes of US and Europe yield curves have some
\end{abstract}


information content (not implicitly present in the slope of the Spanish yield curve) that helps to better forecast the probability of bear markets in the IBEX 35 .

KEY WORDS: Term structure of interest rates, Stock returns, Trading strategies JEL CODES: E43, G15, C20 


\section{Introduction.}

There is a growing amount of literature studying the predictive power of the term structure of interest rates (also known as yield curve) over the business cycle. Following the findings of Harvey (1988), a large empirical literature has documented the excellent leading indicator properties of the slope of the yield curve, defined as the difference between long and short-term interest rates, for future economic activity.

Stock and Watson (1989) found that interest rate spreads added value to their multivariate index of leading economic indicators. Evidence on the ability of the yield curve slope to predict real economic activity has then been put forward by, e.g., Estrella and Hardouvelis (1991) and Estrella and Mishkin (1996) for the United States of America (US) and Estrella and Mishkin (1998) and Plosser and Rouwenhorst (1994) for several industrialized countries. More recently, it has been shown that the yield slope has a good record in forecasting recessions in real-time (e.g. see Estrella and Trubin, 2006) and has marginal predictive power for US recessions over the Survey of Professional Forecasters (Rudebusch andWilliams, 2009). Besides, the relevance of the yield slope has even been reinforced in the framework of iterative forecasting procedures produced by more complex dynamic models (e.g. see Kauppi and Saikonen, 2008).

At the same time that the leading indicator property of the term spread for economic activity has been documented, there is also a branch in literature investigating if the yield curve is a leading indicator of the stock market. It answers a capital question for theoretical economists and market practitioners as the following: do the macroeconomic signals given by the yield curve contain usable information on trading in the stock markets? 
Many researchers have investigated the relation between yield curves and financial asset returns. Fama and French (1989) show that excess returns on US stocks and corporate bonds are positively related to the slope of the yield curve of US Treasury securities. These authors say that the yield curve has predictive ability because it is a proxy for discount rate shocks. Both stocks and long-term Treasury bonds are long-term investments, and are highly susceptible to changes in investors' intertemporal discount rates. Siegel (1998) suggested that a market timing strategy based on exchanging T-bills for stocks four months before peaks and the contrary before troughs may be applied whether the turning points on the business cycles are rightly predicted four months ahead.

Boudoukh, Richardson, and Smith (1993) and Ostdiek (1998) show how ex ante risk premiums on US stocks and the world stock portfolio are negative in periods preceded by inverted yield curves. For individual foreign countries, the research has been limited, although Asprem (1989) examined the relationship between the US term spread and the returns on stocks of ten European countries. McCrown (2001), meanwhile, looks at the effects of foreign country yield curves on the risk premiums of their own stocks, and study the effects of the larger economies' yield curves (US, Germany and Japan) in the smaller countries' stocks finding empirical evidence about the relationships between yield curves and risk premiums of stocks for eight industrialized countries.

Resnick and Shoesmith (2002) use the yield curve to forecast the probability of S\&P 500 being present in a bear market within several periods. They find that term spread (10 years US T-Bond minus 3 months US T-Bill) or slope in the yield curve of US is a powerful predictive variable for bear markets in S\&P 500 .

In this paper we present a model to forecast the probability of bear markets in the Spanish IBEX 35, a market capitalization weighted index of the 35 most liquid Spanish 
stocks in the Madrid Stock Exchange, with a congruent and concise parameterization which selects the explanatory factors from a wide set of variables like the yield curve of Spain, US and Europe, as well as several macro variables, and numerous leading indicators. To that end, we use an algorithm only guided by data in order to select the in-sample optimal Probit model which has been widely used in investigating the ability of yield curve as a predictor of economic recessions (see Estrella and Mishkin, 1996, 1998).

The reason for using a Probit model in our work is the poor performance of all the existing structural models and VAR models, which has motivated a different approach to turning points forecasting developed by Estrella and Hardouvelis (1991) and followed by Estrella and Mishkin (1996, 1998) among others. Probit approach recognizes that statistical models that are used in forecasting future values of economic time series may not be useful in predicting recessions. So, instead of using linear regressions models, they directly study the probability of a recession using a Probit model, where the variables included inside and their respective coefficients are chosen on the basis of their ability to indicate the likelihood of past recessions and not on the basis of their ability to track past movements in real GDP. So, in their seminal paper, Estrella and Mishkin (1996, 1998) put forward a Probit model to forecast if US economy suffers a recession within several quarters. For this purpose, they take financial, macroeconomic and economic indicators within their Probit model as variables to forecast that probability.

Our paper implements a technical trading rule on the Spanish stock market index based on predicting the turning points of the stock market through a Probit model, and using explanatory factors from a wide set of variables like the yield curve of Spain, US and Europe, as well as several macro variables, and numerous leading indicators. Besides, 
an optimal Probit model containing a concise parameterization is obtained using a genetic algorithm. Our paper has two main contributions. On the one hand, the Probit model of Resnick and Shoesmith (2002) is applied to the most important stock market index of Spain, IBEX 35. On the other hand, we carry out a broad study to find which variables have the highest predictive power over bear markets in IBEX 35. To that end, we split the yield curve on three components (level, slope and curvature) to check if any of them, individually or in combination with others, has predictive power. Therefore, our paper is connected to the growing literature that studies whether components of yield curve incorporate any important information about future evolution in macroeconomic aggregates (Ang et al., 2006; Diebold et al., 2006; Moench, 2012; Ferreira et al., 2008, among others). Given that Spain has a relatively small economy, it is worth assessing whether the implicit information on yield curve of its main partners, i.e., US and Europe, may improve the predictive power of the Spanish yield curve. This is particularly interesting given the fact that over recent decades, Spain has registered a steady increase in cross-border financial flows from and to the rest of the world. The efforts made in the last decade for many Spanish financial institutions including banks and institutional investors to advance their international expansion is still essential to mitigate the effects on operating accounts of the severe recession being experienced by the Spanish economy.These developments reflected the progressive dismantling of controls on cross-border financial flows as well as the liberalisation of national financial markets more generally. Regarding this, we combine the components in yield curves in Spain, US and Europe in a similar fashion to Harvey (1997). Finally, we employ an optimal model selection algorithm called GASIC (Acosta-Gonzalez and FernandezRodriguez, 2007) to find the best possible model using as variables a broad set of 
financial, macroeconomic and economic indicators. This optimal model is our benchmark.

The paper is structured as follows. Section 2 introduces the Probit model. Section 3 presents the data. The GASIC algorithm and the optimal Probit model are explained in Section 4. Sections 5 and 6 provide goodness of prediction and economic performance for different models, respectively. Section 7 offers some concluding remarks.

\section{Probit model.}

Estrella and Mishkin (1998) put forward a Probit model to quantify the predictive power of several economic and financial variables over future recessions. Meanwhile, Resnick and Shoesmith (2002) adapt the former to obtain the probability of bear markets in S\&P 500. Thus, the Probit model for a bear market, one month ahead, in any stock market index is the following,

$$
P\left(R_{t+1}=1\right)=\Phi\left(\alpha_{0}+\sum_{i=1}^{N} \alpha_{i} X_{t, i}\right)
$$

where, $\Phi(\cdot)$ is the cumulative normal probability density function; $X_{t, i}$ are the variables to explain the bear markets; $N$ is the number of variables and $R_{t}$ is a binary variable which codifies the stock market index in month $t$ as

$$
R_{t}= \begin{cases}1, & \text { bear market in stock market index in } \mathrm{t} \\ 0, & \text { otherwise }\end{cases}
$$

To define a bull or bear market is not a trivial task because there is no consensus in the literature about how to identify them. In this sense, several methodologies have been developed to guess where the stock market is at present. Among all of them and given its simplicity and ease to read, we employ the nonparametric Bry-Boschan algorithm (Bry and Boschan, 1971) also used in Candelon et al. (2008) to that end. The key idea 
of this algorithm is to find the turning points of the market (peaks and troughs) which are the maximum and minimum locals in the stock market index. So a peak (trough) in stock market index $\left(p_{t}\right)$ occurs when $p_{t}$ finds a local maximum (minimum) in a sixmonth window. Specifically, the Bry-Boschan algorithm finds a peak in month $t$ if,

$$
\begin{aligned}
& p_{t-i}<p_{t}, \quad i=1, \ldots, 6, \text { and } \\
& p_{t+i}<p_{t}, \quad i=1, \ldots, 6
\end{aligned}
$$

and a trough if,

$$
\begin{aligned}
& p_{t-i}>p_{t}, \quad i=1, \ldots, 6, \text { and } \\
& p_{t+i}>p_{t}, \quad i=1, \ldots, 6
\end{aligned}
$$

Finally, a bear (bull) market is that period between a peak (trough) and a trough (peak) that it is defined as $R_{t}=1\left(R_{t}=0\right)$. Once $R_{t}$ is defined, equation (1) is estimated through the following maximum likelihood function,

$$
L=\prod_{R_{t+1}=1} P\left(R_{t+1}=1\right) \prod_{R_{t+1}=0}\left[1-P\left(R_{t+1}=1\right)\right] .
$$

In literature, several methodologies have been developed to test the goodness of fit in Probit model. In this paper, Estrella's (1998) pseudo- $R^{2}$ is employed. This is an easy-todeploy goodness of fit statistic based on broadly used $R^{2}$ of linear regressions. The pseudo- $R^{2}$ is defined as follows,

$$
\text { pseudo- } R^{2}=1-\left(\frac{L_{u}}{L_{c}}\right)^{-(2 / T) L_{c}}
$$

where, $L_{u}$ is the maximum value in the logarithm of the likelihood function in Probit model, $L_{c}$ is the maximum value in the logarithm of the likelihood function under hypothesis all the parameters of the model, but the constant, are null and $T$ is the sample length. The pseudo- $R^{2}$ takes values between 0 and 1 , following the same meaning than $R^{2}$ of linear regressions. 


\section{Data.}

In our paper, we have worked with different monthly economic times series which might be classified within three sets: yields of the sovereign debt (provided by Bank of Spain, FED and Eurostat); components of the yield curve (level, slope and curvature) ${ }^{1}$; and financial, macroeconomic and economic indicators variables (provided by website of Spain's Minister of Economy).

In the following Table 1, the list of variables used in this paper is shown, all of them having some information about economy activity. As can be seen, these variables are leading or coincident economic indicator commonly used in the analysis of current economic performance and in predictions of future performance. Our sample spans February 1991 to December $2009^{2}$, given that some variables do not have continuous information before February 1991.

\section{[Insert Table 1 here]}

As Resnick and Shoesmith (2002), we take the logarithm of IBEX 35 to test whether this is in a bull or bear market within one month. Figure 1 plots the evolution in the logarithm of IBEX 35 where shaded area stands for bear markets according to BryBoschan algorithm.

\section{[Insert Figure 1 here]}

In order to test the in-sample goodness of fit and out-of-sample goodness of prediction, our sample has been split into two periods: February 1991 and January 2003 for insample period and February 2003 and December 2009 for out-of-sample period.

\section{The GASIC algorithm.}

\footnotetext{
${ }^{1}$ Following to Diebold, Rudebusch and Aruoba (2006), level is calculated as the mean of all the yields, slopes as 3 months T-Bill minus each one of the other yields and curvature as twice the 2 years T-Bond minus 3 months T-bill and 10 years T-Bond.

${ }^{2}$ Even though our sample ended in June 2010, we had to eliminate the latest six months due to BryBoschan algorithm.
} 
Our study is carried out with 53 time series (aside from the logarithm of IBEX 35) that are employed in Probit model to forecast the probability of bear markets, one month ahead, in IBEX 35. Hence, there exist $2^{53}=9,007,199,254,740,990$ Probit models to choose from. So it would take too much computational time to assess one by one such a big number of possible models. Thus, we have employed GASIC algorithm (AcostaGonzález and Fernández-Rodríguez, 2007) to find the optimal econometric model.

Our GASIC seeks the optimal Probit model through a Genetic Algorithm (GA) ${ }^{3}$ by means of Schwarz Information Criterion (SIC) as objective function. Besides, GASIC avoids overparameterization, i.e., the GASIC's optimal model has usually a small number of variables. Thus, the properties of congruence and concise parameterization are satisfied (Hendry, 2001).

The optimal Probit model selected by GASIC is reported in the following Table 2. In addition, the t-test corrected by Newey-West, pseudo $-R^{2}$ and Schwarz Information Criterion (SIC) are also reported.

\section{[Insert Table 2 here]}

As we expected, the optimal Probit model obtains a high pseudo- $R^{2}(0.9576)$ which is higher than that obtained by Resnick and Shoesmith (2002) for S\&P 500. Regarding the signs in variables, we can see how variables that reduce the probability of a bear market in IBEX 35 are: 10 years yield of Europe; composite leading indicators (trend); DOW JONES index; and backlog level construction sector. With the exception of DOW JONES index, all these variables are indicators of the strength in either Spanish economy (trend of composite leading indicators or backlog level construction sector) or Europe economy (10 years yield of Europe) that reflects the potential of the corporations in IBEX 35.

\footnotetext{
${ }^{3}$ Genetic Algorithms (GA) are a class of adaptive search and optimization technique based on the principles of natural evolution, initially developed by Holland (1975).
} 
Instead, the variables that increase that probability are: 5 years yield of Spain; 5 years yield of US; 2 years yield of Europe; slope of Spain $(3 \mathrm{~m}-2 \mathrm{y})$; consumer price index (CPI); imports; total manufacturing backlog; composite leading indicators (amplitude adjusted) and NASDAQ index. In general, these variables are linked to possible cyclical deviations of the economy ( 5 years yield of Spain; 5 years yield of US; 2 years yield of Europe; amplitude adjusted of composite leading indicators or slope of Spain), weakness in the industrial sector (total manufacturing backlog), inflationary pressures (CPI) or substitution of national for foreign production (imports).

It is interesting to see how DOW JONES index has a negative effect on the probability of bear markets, one month ahead, in IBEX 35 but, instead, NASDAQ index has a positive effect. The former could be explained by a complementary relationship between IBEX 35 and DOW JONES (broadly speaking, both gather same type of economic sectors) and a substitutability relation between IBEX 35 and NASDAQ (hightech companies in electronics, IT, telecommunications, biotechnology, etcetera are represented in NASDAQ but these companies are less represented in IBEX 35).

Figure 2 shows, aside from what we plot in Figure 1, the in-sample probability of bear markets, one month ahead, in IBEX 35 with the optimal Probit model.

[Insert Figure 2 here]

Finally, our benchmark is the best possible model given by our variables, i.e., the optimal Probit model selected by GASIC.

\section{Prediction of bear markets in IBEX 35.}

Here, the goodness of prediction in the optimal Probit model is compared with several one variable Probit models formed by slope in yield curve, consumer price index (CPI), unemployment rate (UR) or industrial production index (IPI), all of them from Spain, as 
in Resnick and Shoesmith (2002) and Chen (2009), among others. Besides, Probit models formed by combinations in yield curves' components of Spain, US and Europe are also reported. In Table 3, the 18 Probit models used in our paper are shown. To avoid any misunderstanding with the optimal Probit model, these variables are represented by $z_{i}{ }^{4}$

\section{[Insert Table 3 here]}

The prediction of bear markets is not as naïve a task as it seems due to Bry-Boschan algorithm not being able to identify what the actual market (bear or bull) is without suffering look-ahead bias. In order to solve this issue, iterative predictions are done in the previous six months to the month that we actually want to forecast, $\hat{R}_{t-i}$ with $i=\{0,1,2, \ldots, 5\}$, using all the available information from the first month of the sample, and then codifying them as

$$
\hat{R}_{t-i}=\left\{\begin{array}{l}
1 \Leftrightarrow P\left(\hat{R}_{t-i}=1\right) \geq 50 \% \\
0 \Leftrightarrow P\left(\hat{R}_{t-i}=1\right)<50 \% .
\end{array}\right.
$$

Once these iterative predictions are obtained, we take the real data from the first month of the sample until the month $t-6,\left\{R_{1}, R_{2}, \ldots, R_{t-6}\right\}$, and the iterative (and codified) predictions until month $t,\left\{\hat{R}_{t-5}, \hat{R}_{t-4}, \hat{R}_{t-3}, \hat{R}_{t-2}, \hat{R}_{t-1}, \hat{R}_{t}\right\}$, to forecast the probability of a bear market in month $t+1, P\left(\hat{R}_{t+1}=1\right)$. After this, we increase the models in one month and repeat all the former steps. This process is repeated until the last month of the sample is forecasted.

The goodness of prediction is evaluated through four statistics: the root-mean-square error (RMSE), Quadratic Probability Score (QPS) of Diebold and Rudebush (1989) and the out-of-sample pseudo- $R^{2}$.

The QPS is as follows,

\footnotetext{
${ }^{4}$ Annex A reports the in-sample results for Probit models of Table 3.
} 


$$
Q P S=T^{-1} \sum_{t} 2\left[P\left(\hat{R}_{t+1}=1\right)-R_{t+1}\right]^{2}
$$

where, $T$ is the out-of-sample length, $P\left(\hat{R}_{t+1}=1\right)$ is the predicted probability of bear markets one month ahead, and $R_{t+1}$ is the real binary variable for bear markets in month $t+1$. QPS is bounded between 0 and 2 where 0 means a perfect approximation to the real probability. On the other hand, the out-of-sample $p$ seudo- $R^{2}$ has the same meaning as in-sample one but now it is not bounded between 0 and 1 where a negative value means a poor goodness of prediction.

The findings of goodness of prediction (RMSE, QPS and out-of-sample pseudo- $R^{2}$ ) for all the Probit models are reported in Table 4.

[Insert Table 4 here]

These results may be summarized as follows:

a. Goodness of prediction in the optimal Probit model (GASIC) is poor due to insample over-fitting, possibly.

b. Only models formed by combinations of slopes (models 5 and 7) or levels (model 3) obtain positive out-of-sample pseudo- $R^{2}$.

c. The Probit model with the best goodness of prediction is that formed by slopes of Spain and Europe (model 7).

Our findings are in line with literature confirming that the slope in yield curve of Spain is the best predictor of bear markets in IBEX 35. Nevertheless, they go beyond showing that the probability of bear markets may be improved whether the slopes of Spain, US and/or Europe are combined. Thus, we have proved that the slopes of US and mainly Europe add some information, not implicit in the slope of Spain, to the probability of bear markets, one month ahead, in IBEX 35. This result is consistent with the growing integration of the Spanish stock market with the world economy, making the volatility 
and trends of the index not only sensitive to the national territory but also induces a high exposure to the news coming from the Eurozone and US.

\section{Trading strategy.}

In this section, we analyse if the predicted probability of bear markets may be exploited in a trading strategy. To do so, we have replicated the naïve trading strategy carried out by Resnick y Shoesmith (2002) over the out-of-sample period. In this strategy, positions are taken each month and held for one month as follows:

If $P\left(\hat{R}_{t+1}=1\right) \geq$ Strategy limit $\Leftrightarrow$ To invest in the risk free asset.

If $P\left(\hat{R}_{t+1}=1\right)<$ Strategy limit $\Leftrightarrow$ To invest in IBEX 35 .

where $P\left(\hat{R}_{t+1}=1\right)$ is the predicted probability of bear markets, one month ahead, in IBEX 35, risk free asset is the 3-month T-Bill of Spain and, as strategy limits, we use a $30 \%, 40 \%$ and $50 \%$, respectively. Moreover, transaction costs $(0.20 \%)$ are applied each time a position is changed. Lastly, we take Buy and Hold (B\&H) strategy as benchmark and assess the performance of strategies with Sharpe ratio (Sharpe, 1966, 1994).

Table 5 reports the annualized mean return and Sharpe ratio of all the strategies and B\&H in out-of-sample period (February 2003-December 2009) for 30\%, 40\% and 50\% as strategy limits.

\section{[Insert Table 5 here]}

As summary, we see the following in Table 5:

a. The optimal Probit model (GASIC) obtains the lowest Sharpe ratio. Also, this is the only model with a negative mean return for any strategy limit. 
b. Most of the models obtain the same mean return ( $8.12 \%$ per annum) and Sharpe ratio $(0.1321)$ than $\mathrm{B} \& \mathrm{H}$ so they are not able to forecast any bear markets in the out-ofsample period.

c. The models with the highest mean return and Sharpe ratio are those formed by combinations of slopes (models 5 and 7) with a $15.37 \%$ per annum and 0.3616 on average, respectively.

d. The strategy limit with highest Sharpe ratio, on average, is $30 \%$.

Therefore, we have proved empirically that Probit models with slopes of Spain, US and Europe (model 5) or slopes of Spain and Europe (model 7) get the best goodness of prediction for the probability of bear markets, one month ahead, in IBEX 35. Besides, exploiting those predictions in a naïve trading strategy overcomes to B\&H strategy.

\section{Concluding remarks}

In this paper, a Probit model proposed by Estrella and Mishkin (1998) and Resnick and Shoesmith (2002) has been used to forecast the probability of bear markets, one month ahead, in the IBEX 35 index, a market capitalization weighted index of the 35 most liquid Spanish stocks in the Madrid Stock Exchange. For this purpose, we have used the in-sample (February 1991-January 2003) optimal Probit model, selected by GASIC algorithm, as a benchmark. Alternatively, several Probit models formed by combinations of levels, slopes and/or curvatures in yield curve of Spain, US and Europe, in addition, several macro variables as in Chen (2009), have been employed to forecast the probability of bear markets in out-of-sample period (February 2003December 2009) and compared with that from the benchmark model.

Our results indicate that the optimal Probit model rendered the best in-sample goodness of fit but the worst out-of-sample performance. In this sense, Probit models formed by 
slopes of Spain, US and Europe and slopes of Spain and Europe offered the best goodness in prediction, as well as the highest Shape ratio in a naïve trading strategy based on their predictions of bear markets.

Our findings suggest that to combine slopes in yield curve of Spain, US and Europe does improve the prediction of the probability of bear markets, one month ahead, in the IBEX 35. Thus, we have proved that the slopes of US and mainly Europe have some information content (not implicitly present in the slope of the Spanish yield curve), related to the former probability. This result could be reflecting that more than half of billing of the IBEX 35 companies corresponds to the external sector, distributed more or less evenly among the European Union and the rest of the European Union or OECD world (the latter proxied by the US). Besides, the use of these predictions in a naïve trading strategy in IBEX 35 overcomes to B\&H strategy.

Further research could extend this analysis to other countries checking, somehow, the globalization level in the world economy. Also, it could be interesting to analyse what the most influential economies are worldwide, or by regions, through slopes in yield curve of those economies. 


\section{REFERENCES}

Acosta-González, E., Fernández-Rodríguez, F., 2007. Model selection via genetic algorithms illustrated with cross-country growth data. Empirical Economics 33, 313337.

Ang, A., Piazzesi, M., Wei, M., 2006. What does the yield curve tell us about GDP growth? Journal of Econometrics 131, 359-403.

Asprem, M., 1989. Stock prices, asset portfolios and macroeconomic variables in ten European countries. Journal of Banking and Finance 13, 589-612.

Boudoukh, J., Richardson, M., Smith, T., 1993. Is the ex ante risk premium positive? A new approach to testing conditional asset pricing models. Journal of Financial Economics 34, 387-408.

Bry, G., Boschan, C., 1971. Cyclical analysis of time series: Selected procedures and computer programs. National Bureau of Economic Research, Cambridge, MA

Candelon, B., Piplack, J., Straetmans, S., 2008. On measuring synchronization of bulls and bears: The case of East Asia. Journal of Banking and Finance 32, 6, 1022 1035 .

Chen, S., 2009. Predicting the bear stock market: Macroeconomic variables as leading indicators. Journal of Banking and Finance 33, 211-223.

Diebold, F.X., Rudebusch, G. D., 1989. Scoring the leading indicators. Journal of Business 62, 3, 369-391.

Diebold, F.X., Rudebusch, G. D., Aruoba, S.B., 2006. The macroeconomy and the yield curve: A dynamic latent factor approach. Journal of Econometrics 131, 309-338.

Estrella, A., 1998. A new measure of fit for equations with dichotomous dependent variables. Journal of Business and Economic Statistics 16, 198-205.

Estrella, A., Hardouvelis, G. A., 1991. The term structure as a predictor of real economic activity. The Journal of Finance 46, 555-576.

Estrella, A., Mishkin, F., 1996. The yield curve as a predictor of US recessions. Federal Reserve Bank of New York, Current Issues in Economics and Finance, 2:7, 1-6.

Estrella, A., Mishkin, F., 1998. Predicting US recessions: Financial variables as leading indicators. Review of Economics and Statistics, 80, 45-61. 
Estrella, A. Trubin, M., 2006. The yield curve as a leading indicator: Some practical issues. Federal Reserve Bank of New York Current Issues in Economics and Finance, $12: 5,1-7$.

Fama, E., French, K., 1989. Business conditions and expected returns on stocks and bonds. Journal of Financial Economics 25, 23-49.

Ferreira, E., Martínez Serna, M.I., Navarro, E., Gonzalo Rubio, I., 2008. Economic sentiment and yield spreads in Europe. European Financial Management 14, 206-221.

Harvey, C., 1988. The real term structure and consumption growth. Journal of Financial Economics 22, 305-333.

Harvey, C., 1997. The relation between the term structure of interest rates and Canadian economic growth. Canadian Journal of Economics 30, 169-93.

Hendry, D.F., 2001. Econometrics: Alchemy or science? 2nd Edition. Oxford University Press, Oxford.

Holland, J., 1975. Adaptation in Natural and Artificial Systems. MIT Press, Cambridge, MA.

Kauppi, H. Saikkonen, P., 2008. Predicting US recessions with dynamic binary response models. Review of Economics and Statistics 90, 777-791.

McCrown, J. R., 2001. Yield curves and international equity returns. Journal of Banking and Finance 25, 767-788.

Moench, E., 2012. Term structure surprises: The predictive content of curvature, level, and slope. Journal of Applied Econometrics 27, 574-602,

Ostdiek, B., 1998. The world ex ante risk premium: an empirical investigation, Journal of International Money and Finance 17, 967 - 999.

Plosser, C. I., Rouwenhorst, K. G., 1994. International term structures and real economic growth. Journal of Monetary Economics 33, 133-155.

Resnick, B. G., Shoesmith, G.L., 2002. Using the yield curve to time the stock market. Financial Analysts Journal, 58, 82-90. 
Rudebusch, G. D. Williams, J. C., 2009. Forecasting recessions: The puzzle of the enduring power of the yield curve. Journal of Business and Economics Statistics 27, 492-503.

Sharpe, W. F., 1966. Mutual fund performance, Journal of Business 39, 119-138.

Sharpe, W. F., 1994. The Sharpe ratio, The Journal of Portfolio Management 21, 49-58.

Siegel, J. J., 1998. Stocks for the Long Run, 2nd edition. McGraw-Hill, New York.

Stock, J. H., Watson, M. W., 1989. New indexes of coincident and leading economic indicators. NBER Macroeconomics Annual, 351-393. 


\section{ANNEX A \\ GOODNESS OF FIT IN LATENT VARIABLES.}

Resnick and Shoesmith (2002) and Chen (2009), among others, find slope in yield curve of US is a powerful predictive variable of bear markets in S\&P 500. Chen (2009), moreover, states that consumer price index (CPI) has also a predictive power over bear markets. Finally, as in Chen (2009), the unemployment rate (UR) and industrial production index (IPI) are also evaluated.

Table A reports the t-statistics corrected by Newey-West, in-sample pseudo- $R^{2}$ and Schwarz Information Criterion (SIC) for models reported in Table 3. 


\begin{tabular}{|c|c|c|c|c|c|c|c|c|c|c|c|}
\hline \multicolumn{12}{|c|}{ t-statistics corrected by Newey-West, in-sample pseudo- $R^{2}$ and Schwarz Information Criterion (SIC) } \\
\hline Model & $z_{1}$ & $z_{2}$ & $z_{3}$ & $z_{4}$ & $z_{5}$ & $z_{6}$ & $z_{7}$ & $z_{8}$ & $z_{9}$ & pseudo- $R^{2}$ & SIC \\
\hline 1 & -4.0390 & 2.4987 & 4.0010 & - & - & - & - & - & - & 0.1773 & -1.4623 \\
\hline 2 & -0.9049 & 2.5474 & - & - & - & - & - & - & - & 0.0492 & -1.4068 \\
\hline 3 & -3.8619 & 4.0257 & - & - & - & - & - & - & - & 0.1315 & -1.4870 \\
\hline 4 & 0.2515 & - & - & - & - & - & - & - & - & 0.0004 & -1.4345 \\
\hline 5 & -4.2172 & 1.0610 & 4.2825 & - & - & - & - & - & - & 0.1530 & -1.4451 \\
\hline 6 & -1.4875 & 0.0400 & - & - & - & - & - & - & - & 0.0165 & -1.3819 \\
\hline 7 & -4.1696 & 4.1655 & - & - & - & - & - & - & - & 0.1453 & -1.5095 \\
\hline 8 & -1.5157 & - & - & - & - & - & - & - & - & 0.0165 & -1.4514 \\
\hline 9 & 1.1466 & 1.6623 & 3.9211 & - & - & - & - & - & - & 0.2779 & -1.5968 \\
\hline 10 & 4.1866 & 2.0614 & - & - & - & - & - & - & - & 0.1526 & -1.5511 \\
\hline 11 & 0.9757 & 4.0558 & - & - & - & - & - & - & - & 0.2591 & -1.6265 \\
\hline 12 & 4.1055 & - & - & - & - & - & - & - & - & 0.1226 & -1.5699 \\
\hline 13 & -2.5271 & 0.1944 & 4.3565 & - & - & - & - & - & - & 0.1764 & -1.5055 \\
\hline 14 & 0.1096 & -1.0134 & 1.4238 & 0.8175 & -0.7323 & 0.6581 & -0.4974 & 2.0000 & 1.6926 & 0.3292 & -1.2324 \\
\hline 15 & -0.1855 & 1.7716 & 0.3043 & 0.5012 & -0.0834 & 2.3577 & - & - & - & 0.2986 & -1.4078 \\
\hline 16 & 0.4138 & - & - & - & - & - & - & - & - & 0.0012 & -1.4353 \\
\hline 17 & -1.0799 & - & - & - & - & - & - & - & - & 0.0082 & -1.4448 \\
\hline 18 & 0.4403 & - & - & - & - & - & - & - & - & 0.0014 & -1.4357 \\
\hline
\end{tabular}

Table A. $\mathrm{t}$-statistics corrected by Newey-West, in-sample pseudo- $R^{2}$ and Schwarz Information Criterion (SIC) for models reported in Table 3. 
Goodness of fit for latent variables may be summarized as follows:

a. Probit models formed by combinations in curvature of Spain, US and Europe (models 9, 10, 11 and 12) obtain the best goodness of fit according to SIC.

b. Neither CPI nor UR nor IPI are statistically significant.

c. According to SIC, the optimal Probit model (GASIC) obtains a better goodness of fit (-3.3738) than model 11 which is the best Probit model with latent variables ($1.6265)$. 


\section{Table 1. Data.}

\begin{tabular}{|c|c|c|}
\hline Sovereign Debt & Components of Yield Curve & Financials, Macroeconomics and Economic Indicators \\
\hline 3 month yield of Spain & Level of Spain & IBEX $35(\log )$ \\
\hline 2 years yield of Spain & Slope of Spain $(3 \mathrm{~m}-2 \mathrm{y})$ & Consumer Price Index, CPI (log) \\
\hline 3 years yield of Spain & Slope of Spain (3m-3y) & Unemployment rate, UR (log) \\
\hline 5 years yield of Spain & Slope of Spain (3m-5y) & Corporations incorporated (log) \\
\hline 10 years yield of Spain & Slope of Spain $(3 \mathrm{~m}-10 \mathrm{y})$ & Total car registration $(\log )$ \\
\hline 3 month yield of US & Curvature of Spain & Consumer confidence indicator \\
\hline 2 years yield of US & Level of US & Real wage income indicator \\
\hline 3 years yield of US & Slope of US (3m-2y) & Total Exports. Constant prices $(\log )$ \\
\hline 5 years yield of US & Slope of US (3m-3y) & Total Imports. Constant prices $(\log )$ \\
\hline 10 years yield of US & Slope of US (3m-5y) & Imports prices of crude oil, $\$(\log )$ \\
\hline 3 month yield of Europe & Slope of US (3m-10y) & Economic climate indicator \\
\hline 2 years yield of Europe & Curvature of US & Total manufacturing backlog \\
\hline 3 years yield of Europe & Level of Europe & Spain, Composite Leading Indicators, Amplitude Adjusted \\
\hline 5 years yield of Europe & Slope of Europe (3m-2y) & Spain, Composite Leading Indicators, Trend \\
\hline \multirow[t]{7}{*}{10 years yield of Europe } & Slope of Europe (3m-3y) & Industrial Production Index, IPI. Base $2005(\log )$ \\
\hline & Slope of Europe (3m-5y) & EUR/USD \\
\hline & Slope of Europe $(3 \mathrm{~m}-10 \mathrm{y})$ & FED fund rates \\
\hline & Curvature of Europe & DOW JONES Index $(\log )$ \\
\hline & & NASDAQ Index $(\log )$ \\
\hline & & Total new housing $(\log )$ \\
\hline & & Backlog level construction sector \\
\hline
\end{tabular}


Table 2. Variables and t-stat of the optimal Probit model (GASIC) between February 1991 and January 2003.

\begin{tabular}{|c|c|c|}
\hline$x_{i}$ & Variables & t-stat \\
\hline$x_{0}$ & Constant & -2.56 \\
\hline$x_{1}$ & 5 years yield of Spain & 0.60 \\
\hline$x_{2}$ & 5 years yield of US & 2.47 \\
\hline$x_{3}$ & 2 years yield of Europe & 2.41 \\
\hline$x_{4}$ & 10 years yield of Europe & -2.58 \\
\hline$x_{5}$ & Slope of Spain (3m-2y) & 1.93 \\
\hline$x_{6}$ & CPI & 2.49 \\
\hline$x_{7}$ & Imports & 1.73 \\
\hline$x_{8}$ & Total Backlog manufacturing & -1.11 \\
\hline$x_{9}$ & Composite Leading Indicators (Amplitude Adjusted) & 2.55 \\
\hline$x_{10}$ & Composite Leading Indicators (Trend) & -2.34 \\
\hline$x_{11}$ & DOW JONES Index & -2.43 \\
\hline$x_{12}$ & NASDAQ Index & 2.08 \\
\hline$x_{13}$ & Backlog level construction sector & 2.30 \\
\hline pseudo- $R^{2}$ & 0.9576 & \\
\hline$S I C$ & -3.3738 & \\
\hline
\end{tabular}


Table 3. Probit models with latent variables where LEV stands for level, SLO for slope and CURV for curvature in the yield curve of Spain (SP), United States (US) and Europe (EUR), in addition of CPI, UR and IPI.

\begin{tabular}{|c|c|c|c|c|c|c|c|c|c|}
\hline Model & $z_{1}$ & $z_{2}$ & $z_{3}$ & $z_{\mathbf{4}}$ & $z_{\mathbf{5}}$ & $z_{\mathbf{6}}$ & $z_{\mathbf{7}}$ & $z_{\mathbf{8}}$ & $z_{\mathbf{9}}$ \\
\hline $\mathbf{1}$ & LEV SP & LEV US & LEV EUR & - & - & - & - & - \\
\hline $\mathbf{2}$ & LEV SP & LEV US & - & - & - & - & - & - \\
\hline $\mathbf{3}$ & LEV SP & LEV EUR & - & - & - & - & - & - \\
\hline $\mathbf{4}$ & LEV SP & - & - & - & - & - & - & - \\
\hline $\mathbf{5}$ & SLO SP & SLO US & SLO EUR & - & - & - & - & - \\
\hline $\mathbf{6}$ & SLO SP & SLO US & - & - & - & - & - & - \\
\hline $\mathbf{7}$ & SLO SP & SLO EUR & - & - & - & - & - & - \\
\hline $\mathbf{8}$ & SLO SP & - & - & - & - & - & - & - \\
\hline $\mathbf{9}$ & CURV SP & CURV US & CURV EUR & - & - & - & - & - \\
\hline $\mathbf{1 0}$ & CURV SP & CURV US & - & - & - & - & - & - \\
\hline $\mathbf{1 1}$ & CURV SP & CURV EUR & - & - & - & - & - & - \\
\hline $\mathbf{1 2}$ & CURV SP & - & - & - & - & - & - & - \\
\hline $\mathbf{1 3}$ & LEV SP & SLO SP & CURV SP & - & - & - & - \\
\hline $\mathbf{1 4}$ & LEV SP & SLO SP & CURV SP & LEV US & SLO US & CURV US & LEV EUR & SLO EUR & CURV EUR \\
\hline $\mathbf{1 5}$ & LEV SP & CURV SP & LEV US & CURV US & LEV EUR & CURV EUR & - & - \\
\hline $\mathbf{1 6}$ & CPI & - & - & - & - & - & - & - \\
\hline $\mathbf{1 7}$ & UR & - & - & - & - & - & - \\
\hline $\mathbf{1 8}$ & IPI & - & - & - & - & - & - \\
\hline
\end{tabular}


Table 4. Goodness of prediction with RMSE, QPS and out-of-sample pseudo- ${ }^{2}$ between February 2003 and December 2009.

\begin{tabular}{|c|c|c|c|}
\hline Model & RMSE & QPS & pseudo- $R^{2}$ \\
\hline 1 & 0.4783 & 0.4575 & -0.2003 \\
\hline 2 & 0.5059 & 0.5120 & -0.3628 \\
\hline 3 & 0.4377 & 0.3831 & 0.1035 \\
\hline 4 & 0.4655 & 0.4333 & -0.0290 \\
\hline 5 & 0.4128 & 0.3409 & 0.1457 \\
\hline 6 & 0.4686 & 0.4391 & -0.0379 \\
\hline 7 & 0.4101 & 0.3364 & 0.1864 \\
\hline 8 & 0.4679 & 0.4379 & -0.0380 \\
\hline 9 & 0.5480 & 0.6007 & -0.5772 \\
\hline 10 & 0.4926 & 0.4853 & -0.2326 \\
\hline 11 & 0.5369 & 0.5765 & -0.4580 \\
\hline 12 & 0.4743 & 0.4499 & -0.0843 \\
\hline 13 & 0.4968 & 0.4936 & -0.1898 \\
\hline 14 & 0.4467 & 0.3992 & -0.1078 \\
\hline 15 & 0.4728 & 0.4471 & -0.1636 \\
\hline 16 & 0.4852 & 0.4709 & -0.1580 \\
\hline 17 & 0.4637 & 0.4301 & -0.0149 \\
\hline 18 & 0.4673 & 0.4368 & -0.0350 \\
\hline GASIC & 0.8593 & 1.4767 & $<-1.000$ \\
\hline
\end{tabular}


Table 5. Annualized mean return and Sharpe ratios for Probit models, as well as B\&H, with strategy limits of $30 \%$, $40 \%$ and $50 \%$ in outof-sample period (February 2003 and December 2009).

\begin{tabular}{|c|c|c|c|c|c|c|}
\hline \multirow{2}{*}{ Model } & \multicolumn{2}{|c|}{$<30 \%$} & \multicolumn{2}{|c|}{$<40 \%$} & \multicolumn{2}{|c|}{$<50 \%$} \\
\hline & Rent & Sharpe ratio & Rent & Sharpe ratio & Rent & Sharpe ratio \\
\hline 1 & 0.0738 & 0.1215 & 0.0812 & 0.1321 & 0.0812 & 0.1321 \\
\hline 2 & 0.0812 & 0.1321 & 0.0812 & 0.1321 & 0.0812 & 0.1321 \\
\hline 3 & 0.1429 & 0.2934 & 0.0835 & 0.1359 & 0.0812 & 0.1321 \\
\hline 4 & 0.0812 & 0.1321 & 0.0812 & 0.1321 & 0.0812 & 0.1321 \\
\hline 5 & 0.1464 & 0.4285 & 0.1702 & 0.3672 & 0.1394 & 0.2721 \\
\hline 6 & 0.0471 & 0.0919 & 0.0812 & 0.1321 & 0.0812 & 0.1321 \\
\hline 7 & 0.1747 & 0.4559 & 0.1816 & 0.4566 & 0.1097 & 0.1893 \\
\hline 8 & 0.0072 & 0.0141 & 0.0812 & 0.1321 & 0.0812 & 0.1321 \\
\hline 9 & 0.0430 & 0.0741 & 0.0398 & 0.0685 & 0.0428 & 0.0723 \\
\hline 10 & 0.0440 & 0.0746 & 0.0812 & 0.1321 & 0.0812 & 0.1321 \\
\hline 11 & 0.0440 & 0.0759 & 0.0398 & 0.0685 & 0.0576 & 0.0967 \\
\hline 12 & 0.0632 & 0.1118 & 0.0812 & 0.1321 & 0.0812 & 0.1321 \\
\hline 13 & 0.0371 & 0.0653 & 0.0607 & 0.1002 & 0.0812 & 0.1321 \\
\hline 14 & 0.0962 & 0.3093 & 0.1149 & 0.2869 & 0.0981 & 0.2211 \\
\hline 15 & 0.1043 & 0.3714 & 0.1207 & 0.2307 & 0.1081 & 0.1870 \\
\hline 16 & 0.0503 & 0.0848 & 0.0812 & 0.1321 & 0.0812 & 0.1321 \\
\hline 17 & 0.0693 & 0.1163 & 0.0812 & 0.1321 & 0.0812 & 0.1321 \\
\hline 18 & 0.0703 & 0.1157 & 0.0812 & 0.1321 & 0.0812 & 0.1321 \\
\hline B\&H & 0.0812 & 0.1321 & 0.0812 & 0.1321 & 0.0812 & 0.1321 \\
\hline GASIC & -0.0065 & -0.0186 & -0.0105 & -0.0298 & -0.0105 & -0.0298 \\
\hline
\end{tabular}




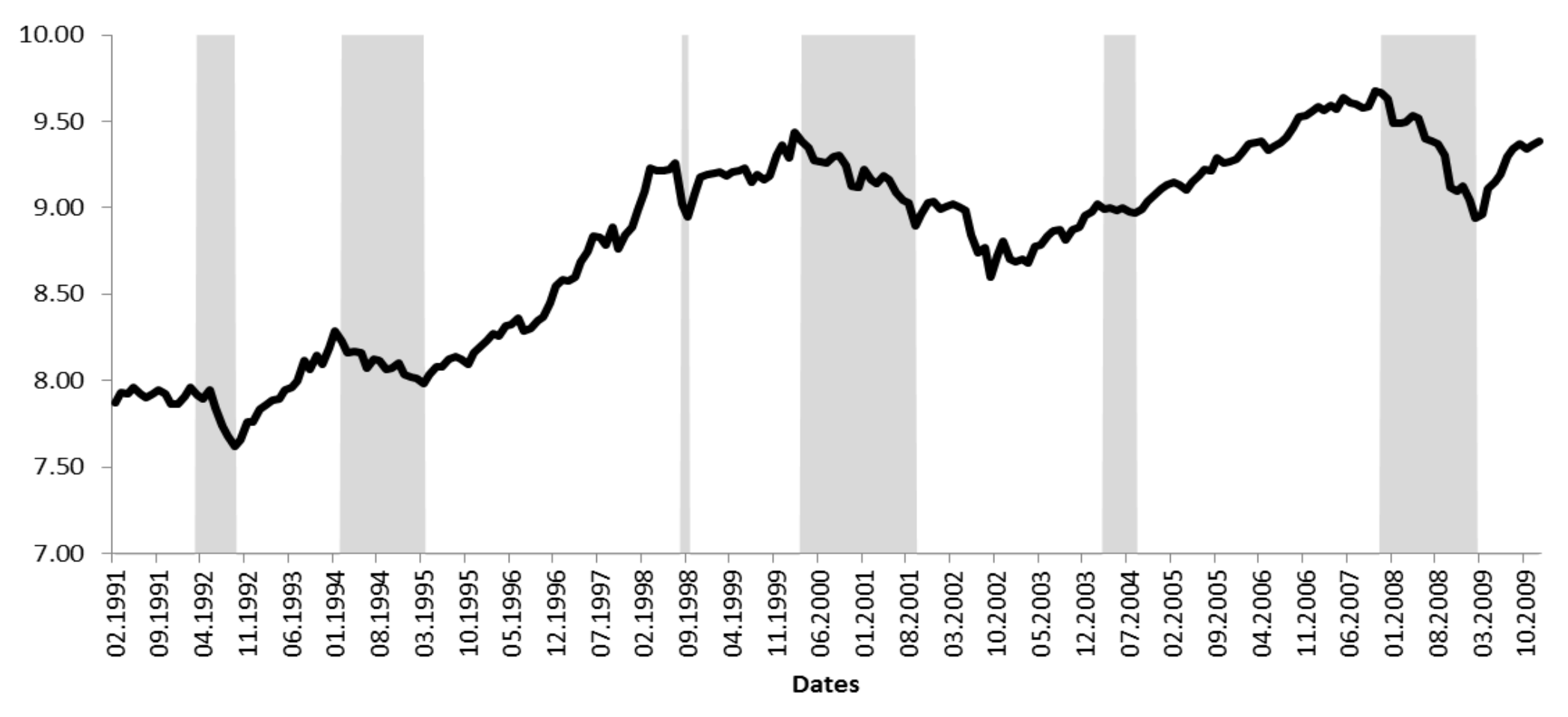

Bear Markets Log(IBEX 35)

Figure 1. Natural logarithm in IBEX 35 between 1991 and 2009. Shaded area is for bear markets according to Bry-Boschan algorithm. 


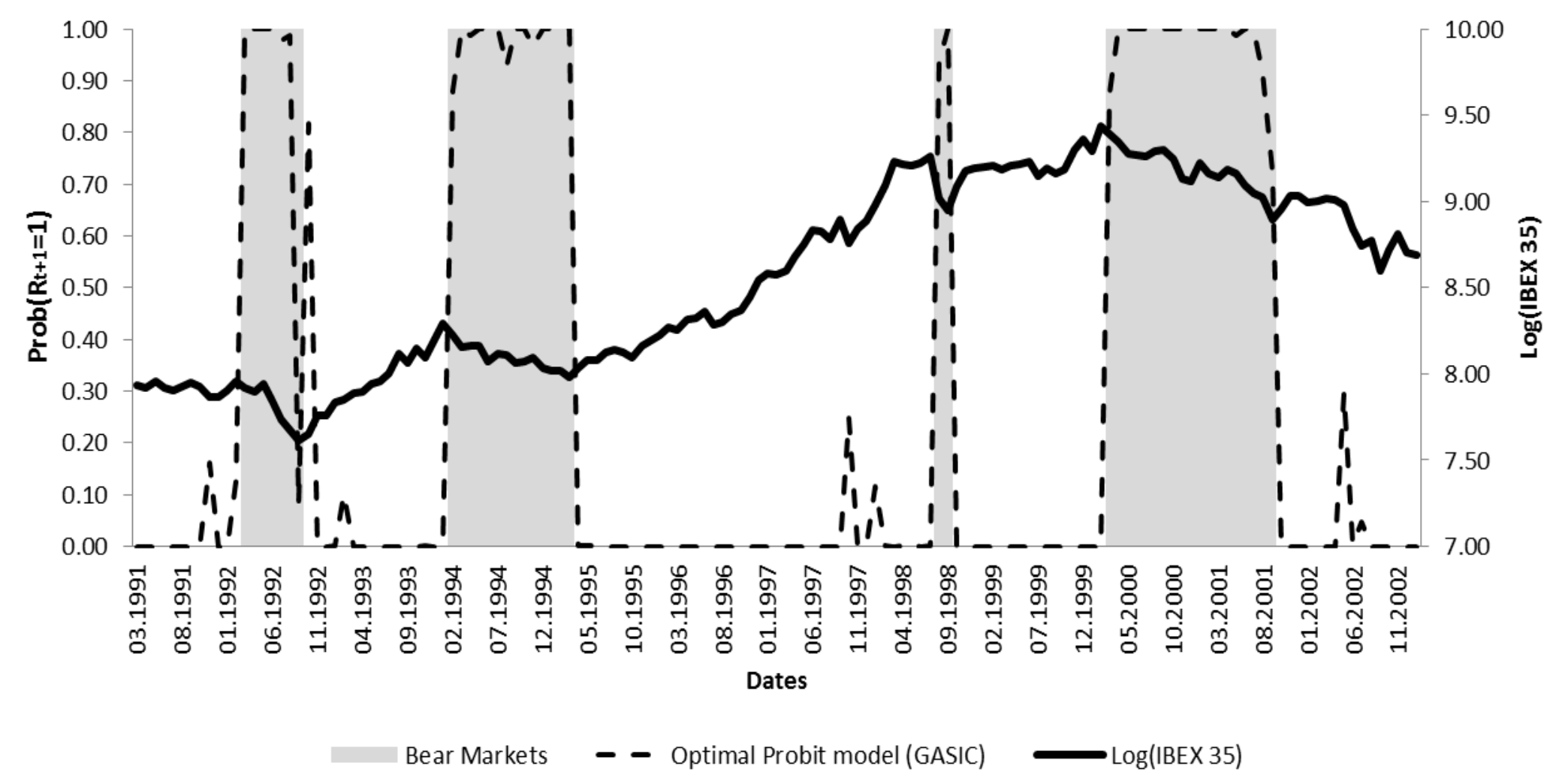

Figure 2. In-sample probability of bear markets, one month ahead, in IBEX 35 with the optimal Probit model (GASIC) and natural logarithm in IBEX 35 . Shaded area is for bear markets according to Bry-Boschan algorithm. 